\title{
Demographic and psychographic drivers of public acceptance of novel invasive pest control technologies
}

\author{
Florian Eppink $^{1}$, Patrick J. Walsh $^{2}$ and Edith MacDonald ${ }^{3}$
}

\begin{abstract}
Invasive mammals are a primary threat to New Zealand's endemic species. In remote areas, aerial delivery of poison is the preferred method of pest management, although it faces some public backlash. Novel pest control technologies are currently being investigated as alternatives but may face similar concerns. To investigate potential social and demographic determinants of public perceptions of new methods for pest control, we conducted a national choice experiment, focused on several novel technologies: gene drives, Trojan females, and species-specific poisons. We found that preferences strongly depend on the type of technology, with Trojan female technology strictly preferred to the other two. Although several characteristics affected preferences in predictable ways education, trust in science, and liberal political leaning increased acceptance - the same did not hold with preferences for aerial delivery. Our results are useful for targeting future engagement campaigns and leveraging existing efforts.
\end{abstract}

Key Words: choice experiment; genetic editing; invasive species; mixed logit; pest control

\section{INTRODUCTION}

New Zealand has some of the most unique endemic species in the world and the highest proportion of species at risk of extinction (MfE 2019). There are 168 native bird species in New Zealand, with the kiwi (Apteryx spp.) being the most famous of the approximately 100 endemic species. Four out of five bird species are threatened by invasive pests (PCE 2017). Large swathes of New Zealand are inaccessible, where spreading poison by hand is not possible. The safest and most cost-effective way to control invasive pests is aerial delivery of the poison sodium fluoroacetate, or "1080" (ERMA 2007, PCE 2011, 2013). However, this method of invasive pest control cannot be scaled up sufficiently to mitigate the enormous pressure from invasive species on New Zealand's biodiversity, indicating a need to develop novel pest control technologies (Russell et al. 2015, Eason et al. 2017). We present a study on public acceptance of novel technologies.

Many new species have been introduced to New Zealand's ecosystem. Certain non-native species such as feral pigs, various deer species, the Himalayan tahr, and Chamois adversely affect native biodiversity but are valued as quarry. Other invasive species are unambiguously seen as pests. Wasp densities can be so high that wasps compete with indigenous birds and insects for honeydew and similar foods (e.g., MacIntyre and Hellstrom 2015). Both ship (Rattus rattus) and Norway ( $R$. norvegicus) rats are competitors (seeds, fruits) and predators (eggs, chicks) of indigenous birds, lizards, insects, and snails (Innes 1990). Stoats (Mustela erminea) are one of the largest threats to New Zealand's native bird populations. They switch to native birds when mammalian prey (mice and rats) become scarce in periodic population cycles (Jones et al. 2011).

Technologies promising larger scale and enduring pest suppression are on the horizon. For instance, new toxins are being developed to control invasive species such as teleost fishes (Sorensen and Stacey 2004), wasps (Edwards et al. 2017), and mammals such as feral pigs (Cowled et al. 2008), feral cats, wild dogs, and stoats (Murphy et al. 2007). Ideally, a new toxin targets only the desired pest. The wasp toxin Vespex is lethal to wasps but safe for birds, mammals, and honey bees (Edwards et al. 2018).

Genetics-based pest control technologies involve the modification, replacement, or deletion of genetic material through an artificial process (Royal Society 2017). Gene drives are one approach to achieving this at scale. These rely on releasing large numbers of edited organisms that have a high chance of propagating their man-made genetic deficiencies (Webber et al. 2015, Courtier-Orgogozo et al. 2017). Examples of such deficiencies are a lethal allele (Schliekelman and Gould 2000) or a skew in offspring sex ratios (Buchman et al. 2018). A variant that is also being explored are Trojan females, where female organisms are genetically altered such that their male offspring have reduced fertility (Wolff et al. 2017).

Novel technologies are often met with public apprehension (e.g., Akin et al. 2017). An important concern identified among the New Zealand public is that technology is advancing faster than our ability to anticipate the risks of its use (Wilkinson et al. 2000, Wilkinson and Fitzgerald 2014). Kirk et al. (2019) found that discussions with New Zealand focus groups were dominated by perceived risks despite awareness of the potential benefits of novel pest control technologies.

The introduction of novel technologies needs to be handled carefully to allay potential public resistance (Goldson et al. 2015) and overcome ideological interpretation or dismissal of scientific information (e.g., Ho et al. 2008, Bain et al. 2012, Milfont et al. 2015). Otherwise, the public may withhold its social license for the use of novel pest control technologies (Wilkinson et al. 2000, Duckworth et al. 2006, Dearden et al. 2017; P. Gluckman 2017, unpublished manuscript, https://www.pmcsa.org.nz/wp-content/ uploads/Discussion-of-Social-Licence.pdf), which may delay cost-effective pest suppression.

${ }^{1}$ Economic \& Environmental Research, ${ }^{2}$ Manaaki Whenua Landcare Research, ${ }^{3}$ New Zealand National Science Challenge 
Table 1. Description of demographic and psychometric variables.

\begin{tabular}{|c|c|c|c|c|c|c|c|}
\hline Category & 1 & 2 & 3 & 4 & 5 & 6 & 7 \\
\hline Age & $18-29$ & $30-39$ & $40-49$ & $50-59$ & $60-69$ & $70+$ & - \\
\hline$\%$ of sample & 14.1 & 16.3 & 16.8 & 18.8 & 19.3 & 14.7 & \\
\hline Gender & Female & Male & Diverse & - & - & - & - \\
\hline$\%$ of sample & 55.1 & 44.6 & 0.3 & & & & \\
\hline Education & None & High school & Tertiary & Bachelor's or higher & - & - & - \\
\hline$\%$ of sample & 7.9 & 29 & 33.9 & 29.2 & & & \\
\hline Science & Strongly trust & Trust & Somewhat trust & Neither trust nor distrust & Somewhat distrust & Distrust & Strongly distrust \\
\hline$\%$ of sample & 1.17 & 3.15 & 10.04 & 27.37 & 35.26 & 19.03 & 3.99 \\
\hline Politics & Extremely liberal & Liberal & Somewhat liberal & $\begin{array}{l}\text { Neither liberal nor } \\
\text { conservative }\end{array}$ & Somewhat conservative & Conservative & Extremely conservative \\
\hline$\%$ of sample & 2.38 & 8.27 & 16.54 & 43.68 & 20.82 & 5.95 & 2.37 \\
\hline Religion & No guidance at all & 2 & 3 & $\begin{array}{c}\text { A moderate amount of } \\
\text { guidance }\end{array}$ & 5 & 6 & A great deal of guidance \\
\hline$\%$ of sample & 43.37 & 14.67 & 7.39 & 13.92 & 6.61 & 5.15 & 8.89 \\
\hline
\end{tabular}

This study presents the results of a national choice experiment on novel technologies to control wasps, rats, and stoats. It is one element of a larger survey ${ }^{[1]}$ aimed at understanding the public's perceptions of and attitudes toward pest control in the context of environmental conservation. The choice experiment focused on sociodemographic influences on preferences for specific aspects of novel pest control technologies, under the hypothesis that they are parallel to preferences for other novel science issues like climate change. The results can be used to develop targeted information campaigns as novel pest control technologies approach operational readiness. Because New Zealand is a critical hot spot for threatened endemic species and shares many characteristics with other developed countries, it serves as an ideal setting to investigate these issues.

\section{METHODS}

\section{Respondent panel and survey development}

The choice experiment was administered to a representative sample of 8200 respondents across New Zealand, representing the largest survey and choice experiment on the social acceptance of novel pest control technologies in New Zealand to date. All respondents were members of the consumer panel of a leading market research firm that has significant experience with social research for the public sector. Using a reputable vendor of respondents rather than recruiting from crowdsourced online panels addressed concerns from an ongoing debate about the response quality of the latter (e.g., Smith et al. 2016, Hauser et al. 2019). Respondents in this study were awarded points in a national loyalty program. The points were redeemable for a range of commercially available goods and services upon completion of the survey. Offering such incentives is a common method among commercial vendors for attracting and retaining panel members with no discernable impact on response quality or survey outcome (e.g., Göritz 2004, Spreen et al. 2019).

Respondents provided demographic indicators, such as age, gender, and education, shown in Table 1. Comparison with the 2013 Census (see Appendix I), which was the reference for the sample design, suggests the respondents were approximately representative of the population of New Zealand. People aged 60 and above were overrepresented, as were women and respondents with tertiary or higher education. The Districts Canterbury, Greater Wellington, and Waikato were underrepresented. Māori, the indigenous inhabitants of New Zealand, were also underrepresented but this was not unusual (e.g., Fink et al. 2011, Kypri et al. 2016).

Much of the larger survey asked respondents to self-report on various values and behaviors, henceforth referred to as "psychometrics." The psychometric indicators used in this study were expressed on a 7-point Likert scale. This balances response variability, accuracy, and respondents' ability to easily identify their position on a scale (e.g., Simms et al. 2019).

A subset of the psychometric indicators, shown in Table 1, was used in the choice models: respondents' belief in the trustworthiness of scientists, their political leaning, and the degree of religious guidance in their daily lives. This selection was inspired by studies by Ho et al. (2008), Bain et al. (2012), and Milfont et al. (2015), as well as a keynote address on novel pest control by New Zealand's Chief Science Advisor, who pointed to trust in the involved actors, world views, and cultural values as important determinants of acquiring a social license for technologies (P. Gluckman 2017, unpublished manuscript).

\section{Choice experiment and econometric analysis}

Choice experiments help understand public preferences by asking respondents to choose between different options (in this case, policies) with varying attributes. By evaluating bundles of attributes for each choice, respondents make trade-offs and so reveal their preferences, which can be analyzed using econometric choice models. In this study, each respondent was shown the same sequence of nine choice tasks. Each choice task asked them to choose between two alternatives that showed a level of each attribute of novel pest control technologies (illustrated in Tables 2 and 3 ). The presentation of the choice experiment is shown fully in Appendix 2.

The alternatives in the choice tasks were identified only as " $\mathrm{A}$ " and "B." In each choice task, respondents were also offered an opt-out phrased as "I do not have a preference" (see Table 3). The opt-out was selected in all nine choice tasks by $12.9 \%$ of respondents. After verifying that the signs, magnitude, and significance of the estimated main parameters were largely unaffected, we removed this group from the sample. Their removal noticeably improved model fit. 
Table 2. Attributes and levels in the choice experiment.

\begin{tabular}{ll}
\hline \hline Attribute & Levels \\
\hline Novel technology & New Poison, Gene Drive, Trojan Female \\
Target animal & Wasps, Rats, Stoats \\
Delivery method & Ground, Aerial \\
Effect & Infertility, Death \\
\hline
\end{tabular}

Table 3. Example of a choice task.

\begin{tabular}{|c|c|c|c|}
\hline & Option 1 & Option 2 & $\begin{array}{c}\text { I do not have a } \\
\text { preference }\end{array}$ \\
\hline $\begin{array}{l}\text { The new pest control } \\
\text { technique }\end{array}$ & New Toxin & New Toxin & \\
\hline $\begin{array}{l}\text { The animal the new } \\
\text { technique would control }\end{array}$ & Rats & Wasps & \\
\hline $\begin{array}{l}\text { How the technique will } \\
\text { be delivered }\end{array}$ & On the ground & On the ground & \\
\hline $\begin{array}{l}\text { What happens to the } \\
\text { animal who interacts } \\
\text { with the new method }\end{array}$ & Infertility & Death & \\
\hline
\end{tabular}

As the number of attributes and levels grows, experimental design quickly becomes challenging. It is more practical to use "efficient" choice experiment design procedures (Rose and Bliemer 2009). Typically, multiple candidate experimental designs are created, which can be evaluated on several measures of efficiency, of which so-called D-efficiency is commonly used. The experimental design for the choice experiment in this study was created by the marketing research firm using Lighthouse Studio (version 9). Multiple designs with high scores for D-efficiency were combined to display each level an approximately equal number of times.

Estimation of the choice model is derived from utility theory. McFadden (1974) posited that the utility function of an individual consists of a deterministic and a random component:

$$
U_{q i t}=\beta X_{q i t}+\varepsilon_{q i t}
$$

where $U_{q i t}$ is utility experienced by person $q$ from alternative $i$ on occasion $t, \beta$ is a vector of utility weights, and $X_{q i t}$ is the vector of attributes in alternative $i$ observed by person $q$. Presented with a choice, individuals are more likely to select one alternative over the other based on (a) the strength of their preferences for the attributes inherent to the choice, (b) the attribute levels present in each alternative in the choice, and (c) a random component $\varepsilon_{q i t}$.

Choice models are developed by estimating $\beta$, the vector of utility weights, which indicate how each attribute and level contribute to the likelihood of an alternative being selected, given the levels of all other attributes. Categorical attributes, which we use exclusively in our model, must have a reference level for which no coefficient is estimated. This ensures the model is identified. However, the likelihood of an alternative being selected is not affected by the choice of reference level, which can therefore be set arbitrarily. The estimated utility weights of categorical attribute levels indicate whether an alternative was more or less likely to be selected compared to the reference level of the attribute.

Estimation of the multinomial logit (MNL) model developed by McFadden (1974) assumes that everyone shares identical preferences for attributes. Extending this simple model, Revelt and Train (1998) presented the mixed logit (MIXL) model, which allowed the diverse preferences of individuals to be estimated. Furthermore, the MIXL model enabled investigation of how individual preferences varied with individual characteristics, including demographics and psychometrics.

Our analysis started with an MNL model of only the attributes of the pest control methods. We added model complexity in a stepwise fashion, starting with an MNL model with interactions between target species and pest control technologies and their possible effects. This first extension aimed to determine whether the New Zealand public perceived a pest control technology or its effect differently for different target species, and whether the model fit improved by including these interactions. We then estimated a basic MIXL model and a MIXL model with the most general error specification, as recommended by Hess and Rose (2012). We assumed individual preferences to have a normal distribution. This second extension aimed to determine whether estimating individual preferences improved model fit, and whether a more general specification of the MIXL model would further improve the results. Finally, we included respondents' demographic and psychometric variables to identify any relation to public preferences. This third extension was exploratory and aimed to find potentially effective avenues for targeted communication.

To assess whether more complex models also better explained respondents' choices, we employed a range of indicators. The Log Likelihood (LL) statistic is used to compare models, signaling improved model fit as the statistic moves toward 0. McFadden's pseudo- $R^{2}$ is an approximation for choice models of $R^{2}$ in statistical analysis, where a value of 0.2-0.4 indicates adequate model performance (McFadden 1974). The Akaike Information Criterion (AIC) and the Bayesian Information Criterion (BIC) are evaluation indicators that use the log likelihood and apply a penalty for adding explanatory variables to prevent overfitting. Smaller values for AIC and BIC indicate better models. We used $R$ (R Core Team 2018) and the $g m n l$ package (Sarrias and Daziano 2017) for model estimation and calculation of performance indicators.

We estimated four models to identify a preferred model specification. Models 1 and 2 are MNL models (assuming homogenous preferences across all respondents) and the latter includes interactions to assess whether the target species affects public preferences for pest control technologies or their effects. Models 3 and 4 are MIXL models that incorporate varying preferences at the individual level. Model 4 uses a more general estimation procedure than Model 3.

To determine if and how public preferences were affected by respondents' demographic and psychometric characteristics, we extended Model 4 to include their age, gender, education, belief in the trustworthiness of scientists (henceforth "Science" for brevity), political leaning ("Politics"), and the degree of religious guidance in daily life ("Religion"). Respectively, these extensions are Models 5 to 10. 


\section{RESULTS}

Model results without demographic or psychometric variables The MIXL Models 3 and 4 performed significantly better than the MNL models on all model evaluation criteria (see Table 4). The LL was reduced from $-64,505$ to $-54,295$ (Model 3) and $-53,015$ (Model 4). McFadden's pseudo- $R^{2}$ increased from 0.045 to 0.242 (Model 3) and 0.26 (Model 4). The AIC and BIC decreased from over 125,000 to around 108,000 (Model 3) and 106,000 (Model 4). The improvements of Model 4 over Model 3 indicated that the more general MIXL model produced the best fit (Likelihood Ratio test: $p=0$, d.f. $=21$ ) for the choice model and was used to study the effect of demographic and psychometric variables.

The estimated coefficients suggested the following preference ordering for technologies: (1) Trojan Female (TF), (2) New Toxin (NT), and (3) Gene Drive (GD). The relative preference for TF was consistent across all models, while the relative preferences for NT (the omitted reference level) and GD had inconsistent signs and statistical significance.

Public preferences for target pest species were clear: positive and significant coefficients indicated that rats and stoats were preferred targets over wasps (the reference level). Across all estimated models, the coefficient for rats indicated relatively strong and stable preferences for this species as a target.

Ground-based delivery of novel pest technology was preferred to aerial delivery (the reference level) with large, positive, and significant coefficients across all models. As an outcome of novel pest control technologies, death was preferred over infertility (the omitted category) across all models. In all models, the estimated coefficient for the opt-out (selecting neither alternative) option was negative and significant.

Comparing Models 1 and 2 shows that including the interaction between target species and pest control technology or its effects did not improve the choice model. The Log Likelihood (LL) and BIC worsened while the other evaluation criteria used did not change. The estimated coefficients for the interaction effects were nonsignificant except for the interaction between Gene Drive (GD) and both rats and stoats. This possibly signaled that the perceived threat of abundant rats and stoats alleviated the concern about GD in general, which is discussed further below.

\section{Demographic and psychometric variables and preferences for novel pest control technologies}

The estimated coefficients and model evaluation scores of Models 5-10 are comparable to Model 4, with a range of LL improvements from 34 points for Model 10 (LR test $\mathrm{p}=0.03, \mathrm{~d}$. f. $=42)$ to 142 points for Model $8($ LR test $p=0$, d.f. $=42)$. The AIC scores improve to various degrees but Models 5-10 tend to score lower than Model 4 on the BIC because of the higher number of variables. The standard deviation of the random parameters in Models 5-10 tended to be lower than in Model 4. Including the demographic and psychometric characteristics of respondents indeed explained a degree of preference variability. Considering the similarity of the results, Models 5-10 are not discussed in detail here but shown in Appendix 3.

The purpose of estimating Models 5-10 was to gain insights on the relationship between preferences and respondents'

demographic and psychometric characteristics. Figure 1 shows the estimated preferences of the demographic and psychometric groups (as shown in Table 1) for GD and TF compared to the reference technology NT. The graphs show the average preference of each group with $95 \%$ confidence intervals. A positive effect indicates preference for that technology over NT, while a negative effect indicates that NT is preferred.

Fig. 1. Group-wise preference for Gene Drive and Trojan Female over New Toxin. Group average with $95 \%$ confidence interval. GD shown in red, TF in blue.

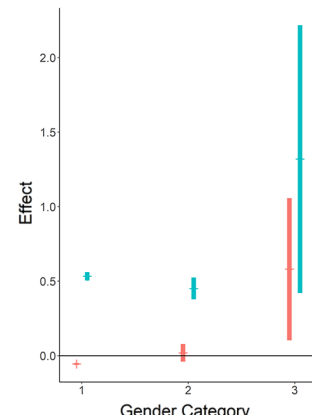

Gender Category

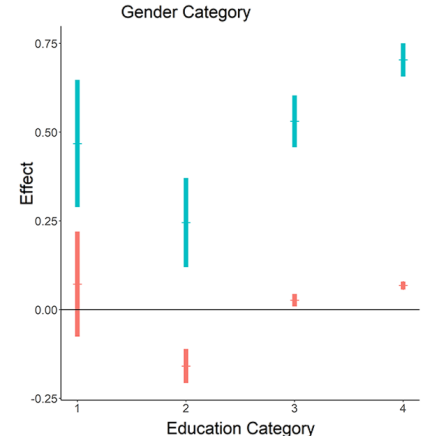

Education Category
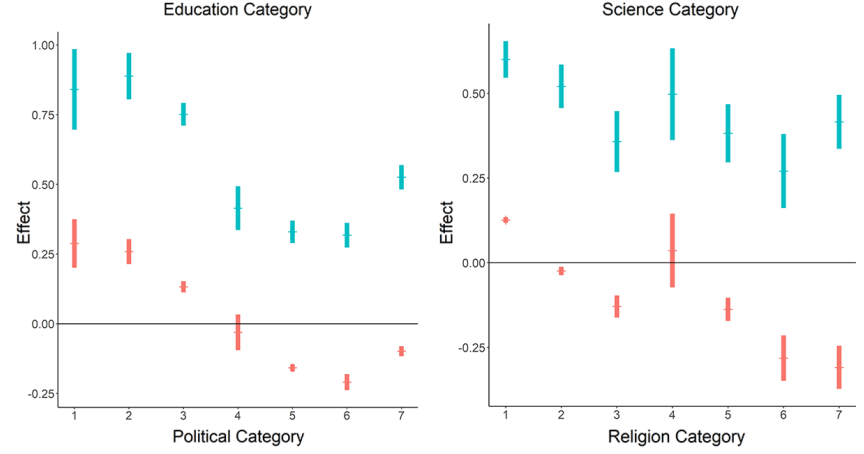

The inclusion of gender, in the top-left pane of Figure 1, suggested that females (1) and men (2) appeared to have only minor differences in preferences for novel pest control technologies. Gender diverse (3) respondents showed a stronger preference for GD and TF over NT but the error margin of this result was high, reflecting the small number of respondents that identified as gender diverse.

Shown in the top-right pane of Figure 1, there is a roughly negative relationship between age and preferences for GD and TF over NT. TF was consistently favored over NT, though this preference became weaker among older respondents. In contrast, preferences for GD over NT were strictly positive only for the youngest group 
Table 4. Estimated choice models without demographics and psychometrics. Coefficients are log odds ratios with standard errors shown in parentheses. All variables are dummy-coded. Random parameters are assumed to have the normal distribution. ${ }^{\dagger \neq}$

\begin{tabular}{|c|c|c|c|c|c|c|c|c|}
\hline & $\begin{array}{c}\text { MNL } \\
\text { Model 1 } \\
\text { Main effects }\end{array}$ & & $\begin{array}{c}\text { Model } 2 \\
\text { Interaction }\end{array}$ & & $\begin{array}{c}\text { MIXL } \\
\text { Model } 3 \\
\text { Main effects }\end{array}$ & & $\begin{array}{c}\text { Model } 4 \\
\text { Correlated } \\
\text { errors }\end{array}$ & \\
\hline \multicolumn{9}{|l|}{ Main effects } \\
\hline Gene Drive & $\begin{array}{c}-0.0152 \\
(0.014)\end{array}$ & & $\begin{array}{c}-0.0613 \\
(0.024)\end{array}$ & $* *$ & $\begin{array}{c}-0.0569 \\
(0.019)\end{array}$ & $* * *$ & $\begin{array}{c}-0.0203 \\
(0.021)\end{array}$ & \\
\hline Trojan Female & $\begin{array}{l}0.3312 \\
(0.018)\end{array}$ & $* * *$ & $\begin{array}{l}0.3307 \\
(0.030)\end{array}$ & $* * *$ & $\begin{array}{l}0.4453 \\
(0.025)\end{array}$ & $* * *$ & $\begin{array}{l}0.5035 \\
(0.026)\end{array}$ & $* * *$ \\
\hline Rat & $\begin{array}{l}0.2278 \\
(0.015)\end{array}$ & $* * *$ & $\begin{array}{l}0.2100 \\
(0.031)\end{array}$ & $* * *$ & $\begin{array}{l}0.3364 \\
(0.020)\end{array}$ & $* * *$ & $\begin{array}{l}0.3404 \\
(0.021)\end{array}$ & $* * *$ \\
\hline Stoat & $\begin{array}{l}0.1039 \\
(0.015)\end{array}$ & $* * *$ & $\begin{array}{l}0.0849 \\
(0.031)\end{array}$ & $* * *$ & $\begin{array}{l}0.1559 \\
(0.020)\end{array}$ & $* * *$ & $\begin{array}{l}0.1446 \\
(0.022)\end{array}$ & $* * *$ \\
\hline Ground & $\begin{array}{l}0.7581 \\
(0.013)\end{array}$ & $* * *$ & $\begin{array}{l}0.7494 \\
(0.014)\end{array}$ & $* * *$ & $\begin{array}{l}1.1788 \\
(0.021)\end{array}$ & $* * *$ & $\begin{array}{l}1.2889 \\
(0.022)\end{array}$ & $* * *$ \\
\hline Death & $\begin{array}{l}0.1227 \\
(0.012)\end{array}$ & $* * *$ & $\begin{array}{l}0.1486 \\
(0.023)\end{array}$ & $* * *$ & $\begin{array}{l}0.1499 \\
(0.017)\end{array}$ & $* * *$ & $\begin{array}{l}0.1506 \\
(0.018)\end{array}$ & $* * *$ \\
\hline Neither (Opt-out) & $\begin{array}{l}-0.3294 \\
(0.018)\end{array}$ & $* * *$ & $\begin{array}{l}-0.3483 \\
(0.027)\end{array}$ & $* * *$ & $\begin{array}{l}-1.1456 \\
(0.031)\end{array}$ & $* * *$ & $\begin{array}{l}-0.9550 \\
(0.034)\end{array}$ & $* * *$ \\
\hline \multicolumn{9}{|l|}{ Interaction terms } \\
\hline Gene Drive x Rat & - & & $\begin{array}{l}0.0663 \\
(0.036)\end{array}$ & $*$ & - & & - & \\
\hline Gene Drive x Stoat & - & & $\begin{array}{l}0.0906 \\
(0.037)\end{array}$ & $* *$ & - & & - & \\
\hline Trojan Female x Rat & - & & $\begin{array}{c}-0.0268 \\
(0.046)\end{array}$ & & - & & - & \\
\hline Trojan Female x Stoat & - & & $\begin{array}{l}0.0096 \\
(0.046)\end{array}$ & & - & & - & \\
\hline Death x Rat & - & & $\begin{array}{l}-0.0222 \\
(0.032)\end{array}$ & & - & & - & \\
\hline Death $x$ Stoat & - & & $\begin{array}{l}-0.0490 \\
(0.032)\end{array}$ & & - & & - & \\
\hline \multicolumn{9}{|c|}{ Standard deviation of random parameters } \\
\hline Gene Drive & & & - & & $\begin{array}{l}1.1430 \\
(0.027)\end{array}$ & $* * *$ & $\begin{array}{l}1.5369 \\
(0.036)\end{array}$ & $* * *$ \\
\hline Trojan Female & - & & - & & $\begin{array}{l}1.2330 \\
(0.041)\end{array}$ & $* * *$ & $\begin{array}{l}0.8360 \\
(0.044)\end{array}$ & $* * *$ \\
\hline Rat & - & & - & & $\begin{array}{l}0.2574 \\
(0.048)\end{array}$ & $* * *$ & $\begin{array}{l}0.7863 \\
(0.040)\end{array}$ & $* * *$ \\
\hline Stoat & - & & - & & $\begin{array}{l}0.3656 \\
(0.044)\end{array}$ & $* * *$ & $\begin{array}{c}-0.1714 \\
(0.045)\end{array}$ & $* * *$ \\
\hline Ground & - & & - & & $\begin{array}{l}1.4340 \\
(0.025)\end{array}$ & $* * *$ & $\begin{array}{l}1.4829 \\
(0.032)\end{array}$ & $* * *$ \\
\hline Death & - & & - & & $\begin{array}{l}1.3233 \\
(0.027)\end{array}$ & $* * *$ & $\begin{array}{l}1.0686 \\
(0.036)\end{array}$ & $* * *$ \\
\hline Neither & & & & & $\begin{array}{l}2.3455 \\
(0.031)\end{array}$ & $* * *$ & $\begin{array}{l}2.2466 \\
(0.031)\end{array}$ & $* * *$ \\
\hline Observations & 64,224 & & 64,224 & & 64,224 & & 64,224 & \\
\hline Log Likelihood & $-62,505$ & & $-64,499$ & & $-54,295$ & & $-53,015$ & \\
\hline McFadden pseudo- $\mathrm{R}^{2}$ & 0.045 & & 0.045 & & 0.242 & & 0.260 & \\
\hline AIC & 125,024 & & 125,025 & & 108,619 & & 106,100 & \\
\hline $\mathrm{BIC}$ & 125,088 & & 125,142 & & 108,746 & & 106,418 & \\
\hline
\end{tabular}

Coefficients are log odds ratios; Standard errors shown in parentheses; $* * * \mathrm{p}<0.01 ; * * \mathrm{p}<0.05 ;{ }^{*} \mathrm{p}<0.1$.

*All variables are dummy-coded. Random parameters are assumed to have the normal distribution.

of respondents. Other age groups tended to prefer NT, though respondents between 50-49 (category 4) showed a small positive average effect, with the confidence interval overlapping with zero.

The effect of education levels on preferences is shown in the middle-left pane of Figure 1. Respondents with high school diplomas (2) had the lowest preference for GD and TF over NT. Tertiary (3) and academic (4) education increased support for GD and TF. The preferences for GD and TF of respondents without a high school diploma (1) were slightly stronger than high school graduates but with a larger margin of error. 
The middle-right pane of Figure 1 suggests that, as respondents' trust in scientists diminished, preferences for GD and TF over NT became less strong. Preferences for TF over NT were consistently positive for all Science groups but not for GD. The respondents that expressed some or no (dis)trust (3-5) in scientists were less supportive than even those that reported a strong distrust of scientists.

The preferences of the political and religious groups are shown in the bottom-left and right panes of Figure 1, respectively. Both groups exhibited weakening preferences for GD and TF as respondents indicated they were more conservative and more religious, although TF was consistently preferred over NT. Preferences for GD were split down political lines, with respondents who self-reported as being politically liberal preferring GD whereas those with conservative political tendencies preferred NT. A similar relationship appeared for the religious groups, although respondents that reported a moderate amount of religious guidance in their daily lives (4) displayed a positive preference with a larger error margin.

We also identified interactions of demographics with preferences for ground and air delivery of pest control. The graph on the left of Figure 2 shows political interactions. Groups 2-7 show a declining preference for ground as they become more conservative and less liberal. However, extreme liberals have a much lower preference for ground than all other groups besides extreme conservatives. The graph on the right shows the impact of age on preferences for ground-based delivery. Middle-aged respondents had the strongest preference for ground delivery, while older and younger groups had much weaker preferences.

Fig. 2. Group-wise preference for ground-based deployment with $95 \%$ confidence interval.
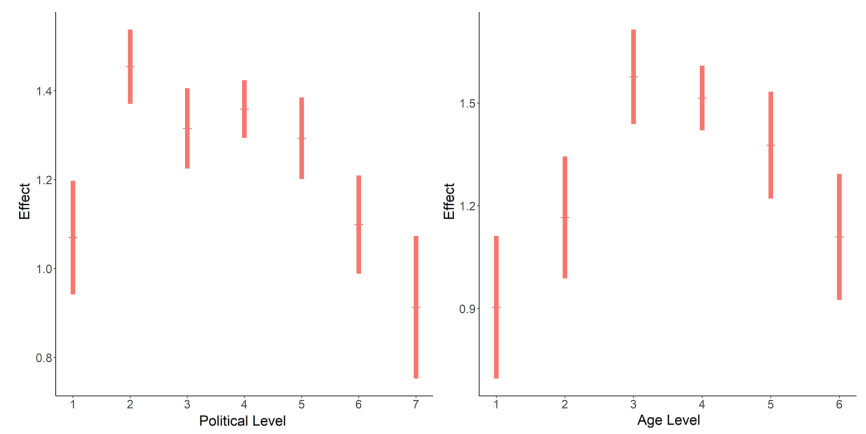

\section{DISCUSSION}

The estimated choice models provided information about the preferences of the New Zealand public for novel pest control technologies, their characteristics, and a few demographic and psychometric variables that correlated with public preferences. These insights could inform communication campaigns when novel technologies become available in the near and medium term but also highlighted aspects of pest control that could be useful in the present.

Our models indicated that the target of novel pest control technology matters. Stoats and particularly rats were favored targets over wasps. This result may reflect that the New Zealand public has long been informed about rats, which have negative impacts outside of biodiversity conservation, and stoats. However, high densities of wasps are mostly found in the honeydew beech forests at the top of New Zealand's South Island. As such, our result may not reflect the preference of New Zealanders living near these forests for target species. A general question about the perceived threat of each pest (Appendix 4) indicates most people do not see wasps as much of a serious threat as rats or stoats. This suggests that public acceptance of novel pest control technologies could be facilitated by widely emphasizing the environmental impacts of pest species in a sustained campaign.

Ground-based delivery of novel pest control technologies was preferred to aerial delivery. This aligned with ongoing distrust of aerial delivery of the poison 1080 in New Zealand (e.g., Green and Rohan 2012), although we found politics and age do affect preferences. Further research would be needed to identify, for instance, whether a rural-urban divide exists or if respondents' own experiences with aerial 1080 operations affect their preferences. Future communication campaigns for novel pest control technologies could emphasize how the perceived risks of these technologies would be mitigated.

Respondents preferred death to infertility. This result may have been particular to New Zealand, which has historically relied on exterminating pest species. Even peri-urban parks with valued biodiversity typically have signs warning visitors about various poisons used to kill pests. These experiences may have caused the respondents to see death as a more effective outcome of pest control technology, or at least desensitized them. Further research could confirm whether the New Zealand public actively dislikes infertility as an effect of pest control technology or whether it simply is comfortable with eradicating pests. Moreover, similar studies in other countries could confirm whether the welfare of pest species more widely is a minor issue for pest control campaigns.

Across all 10 estimated models, we found that preferences for novel technology are strongly dependent on the technology itself, so that it is not just the novelty that drives people's preferences. Although Gene Drive and Trojan Female are both novel technologies, our results indicate that people had a consistent preference for the Trojan Female approach over a New (speciesspecific) Toxin, while preferences for Gene Drive and New Toxin were less clear. Respondents were informed that Gene Drive involved the release of large numbers of modified organisms, whereas Trojan Female required a small number. We speculate that respondents expressed the perceived risk of "swarms" of modified fauna released into New Zealand's unique and sensitive environment in their choices. This concern has been repeatedly identified among New Zealanders (Wilkinson et al. 2000, Wilkinson and Fitzgerald 2014, Kirk et al. 2019).

Our models also investigated how preferences might be affected by respondents' demographic and psychometric traits. People who had more trust in scientists, were more politically liberal, were more secular, or had attained a higher level of education, had a comparatively high acceptance of genetic pest control technology over new toxins. These results suggested that acceptance of these technologies may have been value driven. 
Such prominence of values in accepting science-based facts and technologies has also been identified in discussions about climate change (e.g., Bain et al. 2012, Milfont et al. 2015) and stem cell research (Ho et al. 2008). Groups representing the middle of these traits had more diverse preferences than the more extreme groups, suggesting that "the middle" could be a productive target for communication campaigns to introduce genetic pest control technologies.

Discussing pest control specifically, Russell and Blackburn (2017) note that values can confound scientific discussions and that public debates should accommodate facts as well as perceived pros and cons. Our results appear to bear this conclusion out as groups representing the extremes of age, trust in scientists, and religiosity scales appeared to have well-defined preferences compared to those in the middle.

\section{CONCLUSION}

In this article we present the results of a large, national-level choice experiment in New Zealand about preferences for novel pest control technologies. In a choice experiment, respondents evaluate bundles of different technologies and their attributes, enabling analysis of the trade-offs between attributes in respondents' choices. This allows for a more detailed look into their preferences than asking respondents about these attributes separately and sequentially. The results provide information for communication campaigns about new and future pest control technologies.

The survey focused on three novel technologies for pest control: Gene Drives, Trojan Females, and a New (species-specific) Toxin. We used several econometric models to analyze the responses, including multinomial logit models and mixed logit models. The models also included demographic (age, gender, education) and psychometric (trust in scientists, political leaning, religiosity) variables of the respondents.

Our results provide several insights for communication campaigns about the use of novel pest control technologies as they become operational. First, the respondents strongly preferred novel technology over opting out of a choice. This signaled a general openness to pest control technologies even in the face of perceived risks. Second, the comparative indifference to wasps suggested that the public acceptance of novel pest control technology could benefit from widespread and sustained messaging of the negative impacts of the target species. Third, any new technology relying on aerial delivery may face public resistance simply because of the legacy of the 1080 debate. Fourth, widespread acceptance of novel genetic pest control technologies may hinge on effective communication with "the middle," who as a group are comparatively undecided about their views of these technologies. Finally, because it will take time for technologies to become operational, it will be important to recognize that preferences may shift as people grow older and change. Early communication targeting younger adults might help entrench positive views of future technologies that persist when the technology becomes operational and these adults are older.

Further research can provide more insight into how communication campaigns might be finessed for effective messaging leading to acceptance of novel pest control technologies. For instance, with death being a preferred outcome of pest control methods, would acceptance be equally high if a technology promises reduced fertility? Is there a number of genetically modified organisms released into the environment beyond which the public expresses a nonlinear change in acceptance of the technology? Using larger, more targeted samples across demographic and psychometric traits could improve our understanding of their impact on preferences and acceptance of novel pest control technologies.

${ }^{[1]}$ For additional information about the overall project and the Bioheritage National Science Challenge, see http://www. bioheritage.nz/

Responses to this article can be read online at: https://www.ecologyandsociety.org/issues/responses. php/12301

\section{Data Availability:}

The full survey and the data about public opinions and beliefs supporting the study are available from the New Zealand's Biological Heritage National Science Challenge data repository. Survey link: https:/ldata.bioheritage.nzldataset/survey-data-attitudesnovel-pest-control Public opinion data link: https:/ldata. bioheritage.nz/dataset/public-opinion-pest-control-methods The data from the choice experiment will be provided upon request to the corresponding author and will be added to the repository in the near future.

\section{LITERATURE CITED}

Akin, H., K. M. Rose, D. A. Scheufele, M. Simis-Wilkinson, D. Brossard, M. A. Xenos, and E. A. Corley. 2017. Mapping the landscape of public attitudes on synthetic biology. BioScience 67 (3):290-300. https://doi.org/10.1093/biosci/biw171

Bain, P. G., M. J. Hornsey, R. Bongiorno, and C. Jeffries. 2012. Promoting pro-environmental action in climate change deniers. Nature Climate Change 2(8):600-603. https://doi.org/10.1038/ nclimate1532

Buchman, A., J. M. Marshall, D. Ostrovski, T. Yang, and O. S. Akbari. 2018. Synthetically engineered Medea gene drive system in the worldwide crop pest Drosophila suzukii. Proceedings of the National Academy of Sciences 115(18):4725-4730. https://doi. org/10.1073/pnas.1713139115

Courtier-Orgogozo, V., B. Morizot, and C. Boëte. 2017. Agricultural pest control with CRISPR-based gene drive: time for public debate. EMBO Reports 18(6):878-880. https://doi. org/10.15252/embr.201744205

Cowled, B. D., P. Elsworth, and S. J. Lapidge. 2008. Additional toxins for feral pig (Sus scrofa) control: identifying and testing Achilles' heels. Wildlife Research 35(7):651-662. https://doi. org/10.1071/WR07072

Dearden, P. K., N. J. Gemmell, O. R. Mercier, P. J. Lester, M. J. Scott, R. D. Newcomb, T. R. Buckley, J. M. E. Jacobs, S. G. 
Goldson, and D. R. Penman. 2017. The potential for the use of gene drives for pest control in New Zealand: a perspective. Journal of the Royal Society of New Zealand 48(4):225-244. https://doi. org/10.1080/03036758.2017.1385030

Duckworth, J. A., A. E. Byrom, P. Fisher, and C. Horn. 2006. Pest control: does the answer lie in new biotechnologies? Pages 421-434 in R. B. Allen and W. G. Lee, editors. Biological invasions in New Zealand. Springer, Berlin, Germany. https://doi.org/10.1007/3-540-30023-6 27

Eason, C. T., L. Shapiro, S. Ogilvie, C. King, and M. Clout. 2017. Trends in the development of mammalian pest control technology in New Zealand. New Zealand Journal of Zoology 44(4):267-304. https://doi.org/10.1080/03014223.2017.1337645

Edwards, E., R. Toft, N. Joice, and I. Westbrooke. 2017. The efficacy of Vespex ${ }^{\circledR}$ wasp bait to control Vespula species (Hymenoptera: Vespidae) in New Zealand. International Journal of Pest Management 63(3):266-272. https://doi.org/10.1080/096$\underline{70874.2017 .1308581}$

Edwards, E. D., E. F. Woolly, R. M. McLellan, and R. A. Keyzers. 2018. Non-detection of honeybee hive contamination following Vespula wasp baiting with protein containing fipronil. PLOSONE 13(10):e0206385. https://doi.org/10.1371/journal.pone.0206385

Environmental Risk Management Authority (ERMA). 2007. Reassessment of sodium fluoroacetate (1080) and formulated substances containing 1080 (a vertebrate toxin) by a committee of the Environmental Risk Management Authority. ERMA, Wellington, New Zealand.

Fink, J. W., S.-J. Paine, P. H. Gander, R. B. Harris, and G. Purdie. 2011. Changing response rates from Māori and non-Māori in national sleep health surveys. The New Zealand Medical Journal 124(1328):52-63.

Goldson, S. L., G. W. Bourdôt, E. G. Brockerhoff, A. E. Byrom, M. N. Clout, M. S. McGlone, W. A. Nelson, A. J. Popay, D. M. Suckling, and M. D. Templeton. 2015. New Zealand pest management: current and future challenges. Journal of the Royal Society of New Zealand 45(1):31-58. https://doi.org/10.1080/03$\underline{036758.2014 .1000343}$

Göritz, A. S. 2004. The impact of material incentives on response quantity, response quality, sample composition, survey outcome and cost in online access panels. International Journal of Market Research 46(3):327-345. https://doi.org/10.1177/147078530404600307

Green, W., and M. Rohan. 2012. Opposition to aerial 1080 poisoning for control of invasive mammals in New Zealand: risk perceptions and agency responses. Journal of the Royal Society of New Zealand 42(3):185-213. https://doi.org/10.1080/03036758.2011.556130

Hauser, D., G. Paolacci, and J. J. Chandler. 2019. Common concerns with MTurk as a participant pool: evidence and solutions. Chapter 17 in F. R. Kardes, P. M. Herr, N. Schwarz, editors. Handbook of research methods in consumer psychology. Routledge, New York, New York, USA. https://doi. org/10.4324/9781351137713-17

Hess, S., and J. M. Rose. 2012. Can scale and coefficient heterogeneity be separated in random coefficients models? Transportation 39(6):1225-1239. https://doi.org/10.1007/s11116-012-9394-9
Ho, S. S., D. Brossard, and D. A. Scheufele. 2008. Effects of value predispositions, mass media use, and knowledge on public attitudes toward embryonic stem cell research. International Journal of Public Opinion Research 20(2):171-192. https://doi. org/10.1093/ijpor/edn017

Innes, J. G. 1990. Ship rat. Pages 206-225 in C. M. King, editor. The handbook of New Zealandmammals. Oxford University Press, Auckland, New Zealand.

Jones, C., R. Pech, G. Forrester, C. M. King, and E. C. Murphy. 2011. Functional responses of an invasive top predator Mustela erminea to invasive meso-predators Rattus rattus and Mus musculus, in New Zealand forests. Wildlife Research 38 (2):131-140. https://doi.org/10.1071/WR10137

Kirk, N., R. Kannemeyer, A. Greenaway, E. MacDonald, and D. Stronge. 2019. Understanding attitudes on new technologies to manage invasive species. Pacific Conservation Biology 26(1):35-44 https://doi.org/10.1071/PC18080

Kypri, K., B. Maclennan, and J. L. Connor. 2016. Effects of small incentives on survey response fractions: randomised comparisons in national alcohol surveys conducted in New Zealand. European Journal of Public Health 26(3):430-432. https://doi.org/10.1093/ eurpub/ckw035

MacIntyre, P., and J. Hellstrom. 2015. An evaluation of the costs of pest wasps (Vespula species) in New Zealand. Department of Conservation and Ministry for Primary Industries, Wellington, New Zealand.

McFadden, D. 1974. Conditional logit analysis of qualitative choice behavior. Pages 105-142 in P. Zarembka, editor. Frontiers in econometrics. Academic, Cambridge, Massachusetts, USA.

Milfont, T. L., P. Milojev, L. M. Greaves, and C. G. Sibley. 2015. Socio-structural and psychological foundations of climate change beliefs. New Zealand Journal of Psychology 44(1):17-30.

Ministry for the Environment (MfE). 2019. Environment Aotearoa 2019. Summary. MfE, Wellington, New Zealand.

Murphy, E. C., C. T. Eason, S. Hix, and D. B. MacMorran. 2007. Developing a new toxin for potential control of feral cats, stoats, and wild dogs in New Zealand. USDA/APHIS/WS, National Wildlife Research Center, Fort Collins, Colorado, USA.

Parliamentary Commissioner for the Environment (PCE). 2011. Evaluating the use of 1080: predators, poisons, and silent forests. PCE, Wellington, New Zealand.

Parliamentary Commissioner for the Environment (PCE). 2013. Evaluating the use of 1080: predators, poisons, and silent forests. Update report. PCE, Wellington, New Zealand.

Parliamentary Commissioner for the Environment (PCE). 2017. Taonga of an island nation: saving New Zealand's birds. PCE, Wellington, New Zealand.

R Core Team. 2018. R: A language and environment for statistical computing. Vienna, Austria.

Revelt, D., and K. Train. 1998. Mixed logit with repeated choices: households' choices of appliance efficiency level. Review of Economics and Statistics 80(4):647-657. https://doi. org/10.1162/003465398557735 
Rose, J. M., and M. C. J. Bliemer. 2009. Constructing efficient stated choice experimental designs. Transport Reviews 29 (5):587-617. https://doi.org/10.1080/01441640902827623

Royal Society. 2017. The use of gene editing to create gene drives for pest control in New Zealand. Royal Society New Zealand Te Aparangi - Gene Editing Panel, Wellington, New Zealand.

Russell, J. C., and T. M. Blackburn. 2017. The rise of invasive species denialism. Trends in Ecology \& Evolution 32(1):3-6. https:// doi.org/10.1016/j.tree.2016.10.012

Russell, J. C., J. G. Innes, P. H. Brown, and A. E. Byrom. 2015. Predator-free New Zealand: conservation country. BioScience 65 (5):520-525. https://doi.org/10.1093/biosci/biv012

Sarrias, M., and R. Daziano. 2017. Multinomial logit models with continuous and discrete individual heterogeneity in R: The gmnl package. Journal of Statistical Software 79(2):1-46. https://doi. org/10.18637/jss.v079.i02

Schliekelman, P., and F. Gould. 2000. Pest control by the introduction of a conditional lethal trait on multiple loci: potential, limitations, and optimal strategies. Journal of Economic Entomology 93(6):1543-1565. https://doi.org/10.1603/0022-0493-93.6.1543

Simms, L. J., K. Zelazny, T. Williams, and L. Bernstein. 2019. Does the number of response options matter? Psychometric perspectives using personality questionnaire data. Psychological Assessment 31(4):557-566. https://doi.org/10.1037/pas0000648

Smith, S. M., C. A. Roster, L. L. Golden, and G. S. Albaum. 2016. A multi-group analysis of online survey respondent data quality: comparing a regular USA consumer panel to MTurk samples. Journal of Business Research 69(8):3139-3148. https://doi. org/10.1016/j.jbusres.2015.12.002

Sorensen, P. W., and N. E. Stacey. 2004. Brief review of fish pheromones and discussion of their possible uses in the control of non-indigenous teleost fishes. New Zealand Journal of Marine and Freshwater Research 38(3):399-417. https://doi. org/10.1080/00288330.2004.9517248

Spreen, T. L., L. A. House, and Z. Gao. 2019. The impact of varying financial incentives on data quality in web panel surveys. Journal of Survey Statistics and Methodology 8(5):832-850. https://doi.org/10.1093/jssam/smz030

Webber, B. L., S. Raghu, and O. R. Edwards. 2015. Opinion: Is CRISPR-based gene drive a biocontrol silver bullet or global conservation threat? Proceedings of the National Academy of Sciences 112(34):10565-10567. https://doi.org/10.1073/pnas.1514258112

Wilkinson, R., and G. Fitzgerald. 2014. Social acceptability of the Trojan Female technique for biological control of pests. State of Victoria Department of Environment and Primary Industries, Melbourne, Australia.

Wilkinson, R., G. Fitzgerald, and D. Chittenden. 2000. Public and interest group perceptions of possum fertility controls: a summary of the focus groups. Pages 101-121 in J. Boland, editor. Caught in the headlights: New Zealanders' reflections on possums, control options and genetic engineering. Parliamentary Commissioner for the Environment, Wellington, New Zealand.
Wolff, J. N., N. J. Gemmell, D. M. Tompkins, and D. K. Dowling. 2017. Introduction of a male-harming mitochondrial haplotype via 'Trojan Females' achieves population suppression in fruit flies. eLife 6:e23551. https://doi.org/10.7554/elife.23551 
APPENDIX 1: Comparison of sample composition and 2013 Census data

\begin{tabular}{|c|c|c|c|c|c|}
\hline & $\begin{array}{c}\text { Survey } \\
\text { Sample } \\
(\%) \\
\end{array}$ & $\begin{array}{c}2013 \\
\text { Census } \\
(\%) \\
\end{array}$ & & $\begin{array}{c}\text { Survey } \\
\text { Sample } \\
(\%) \\
\end{array}$ & $\begin{array}{c}2013 \\
\text { Census } \\
(\%) \\
\end{array}$ \\
\hline Gender & & & Household income (NZ\$) & & \\
\hline Male & 44.6 & 47.9 & None & 2.9 & 0.5 \\
\hline Female & 55.1 & 52.1 & $\$ 1-\$ 5,000$ & 1.3 & 0.8 \\
\hline \multirow[t]{2}{*}{ Diverse } & 0.3 & n.a. & $\$ 5,001-\$ 10,000$ & 1.1 & 1.0 \\
\hline & & & $\$ 10,001-\$ 15,000$ & 2.2 & 1.7 \\
\hline Nationality & & & $\$ 15,001-\$ 20,000$ & 3.5 & 2.9 \\
\hline New Zealand European & $74.7^{\mathrm{a}}$ & 72.5 & $\$ 20,001-\$ 25,000$ & 6.1 & 3.2 \\
\hline Maori & $5.6^{\mathrm{a}}$ & 11.2 & $\$ 25,001-\$ 30,000$ & 5.6 & 4.2 \\
\hline \multirow[t]{2}{*}{ Other } & $11.9^{\mathrm{a}}$ & 16.3 & $\$ 30,001-\$ 35,000$ & 5.7 & 4.6 \\
\hline & & & $\$ 35,001-\$ 40,000$ & 5.8 & 3.5 \\
\hline Education & & & $\$ 40,001-\$ 50,000$ & 9.2 & 7.2 \\
\hline None & 8.0 & 20.9 & $\$ 50,001-\$ 60,000$ & 9.0 & 7.5 \\
\hline High school & 29.0 & 40.0 & $\$ 60,001-\$ 70,000$ & 9.0 & 7.3 \\
\hline Tertiary & 33.9 & 19.0 & $\$ 70,001-\$ 100,000$ & 17.7 & 20.2 \\
\hline \multirow[t]{2}{*}{ Bachelor's or higher } & 29.2 & 20.0 & $\$ 100,001-\$ 150,000$ & 13.4 & 19.1 \\
\hline & & & $\$ 150,001$ or more & 6.4 & 16.0 \\
\hline \multicolumn{6}{|l|}{ Age } \\
\hline $18-19$ & 1.7 & $8.8^{\mathrm{b}}$ & Residency & & \\
\hline $20-24$ & 4.9 & 8.6 & Auckland & 12.2 & 33.6 \\
\hline $25-29$ & 7.5 & 7.6 & Bay of Plenty & 6.0 & 6.3 \\
\hline $30-34$ & 7.9 & 7.6 & Canterbury & 6.1 & 12.7 \\
\hline $35-39$ & 8.4 & 7.9 & Gisborne & 3.9 & 1.1 \\
\hline $40-44$ & 7.9 & 9.1 & Hawke's Bay & 6.1 & 3.6 \\
\hline $45-49$ & 8.9 & 8.9 & Manawatu-Whanganui & 6.1 & 5.2 \\
\hline $50-54$ & 8.9 & 8.9 & Marlborough & 6.1 & 1.0 \\
\hline $55-59$ & 9.9 & 7.7 & Nelson & 6.2 & 1.1 \\
\hline $60-64$ & 8.7 & 6.9 & Northland & 6.1 & 3.7 \\
\hline $65-69$ & 10.5 & 5.8 & Otago & 6.1 & 4.7 \\
\hline \multirow[t]{6}{*}{$70+$} & 14.7 & 12.2 & Southland & 6.1 & 2.2 \\
\hline & & & Taranaki & 6.1 & 2.6 \\
\hline & & & Tasman & 6.0 & 1.1 \\
\hline & & & Waikato & 6.1 & 9.6 \\
\hline & & & Wellington & 6.1 & 11.0 \\
\hline & & & West Coast & 4.5 & 0.7 \\
\hline
\end{tabular}

${ }^{a}$ In the sample, $7.8 \%$ of respondents entered multiple nationalities. We excluded these respondents from this table as we do not know their primary nationality.

${ }^{b}$ In the Census, this age group extends down to 15 years. 


\section{APPENDIX 2: Presentation of the choice experiment}
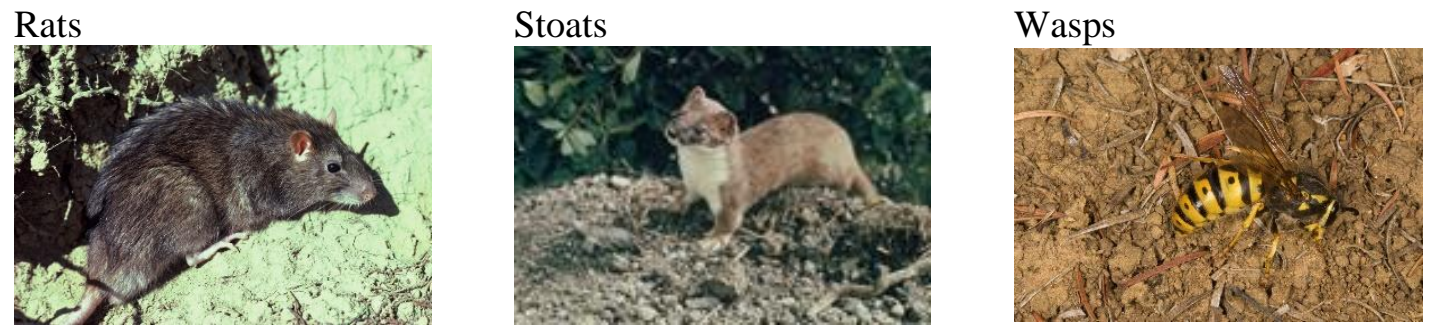

Please read the descriptions of three new techniques below.

\section{Name: New Toxin}

What is it: A new toxin that is species specific (eg it only kills rats) and does not kill other animals. This would be an alternative to 1080 .

\section{Name: Trojan Female}

What is it: Breeding female animals (eg rats) that naturally produce infertile male offspring.

How is it delivered: The Trojan Females are bred in the lab in small numbers and then released into the environment.

How can it eradicate pests: Over time the male offspring in the environment becomes less fertile and the pest population size falls significantly. There is no risk to other species.

\section{Name: Gene Drive}

What is it: An animal's DNA is edited in the lab.

How is it delivered: Large numbers of the animals are bred in a lab and released into the environment to breed with wild animals.

How can it eradicate pests: By infertility or death -

- Infertility - the animals bred in the lab can only produce male offspring. When they breed with wild animals the number of females fall. With fewer females to breed with, the entire population size falls over time.

- Death - the animals bred in the lab pass on a gene to their offspring, which means the offspring die when they eat a certain type of bait. Over time the offspring will die and the population falls.

In the following questions, you will be asked choose between two different options. The set of circumstances for each option will vary. They will include:

\begin{tabular}{|l|l|}
\hline The new pest control technique & $\begin{array}{l}\text { - New Toxin, } \\
\text { The animal the new technique would control }\end{array}$ \\
& $\begin{array}{l}\text { - } \text { Tran female } \\
\text { - Rats, }\end{array}$ \\
\hline How the technique will be delivered & $\begin{array}{l}\text { - Stoats } \\
\text { - On the ground }\end{array}$ \\
\hline $\begin{array}{l}\text { What happens to the animal who interacts with } \\
\text { the new method }\end{array}$ & \begin{tabular}{l} 
- Infertility \\
\hline
\end{tabular} \\
\hline
\end{tabular}


APPENDIX 3: Model results with demographic and psychometric variables. Coefficients are log odds ratios with standard errors shown in parentheses; *** p < 0.01; ** $\mathbf{p}<0.05 ;$ * $<$ < 0.1 ; All variables are dummy-coded; Random parameters are normally distributed

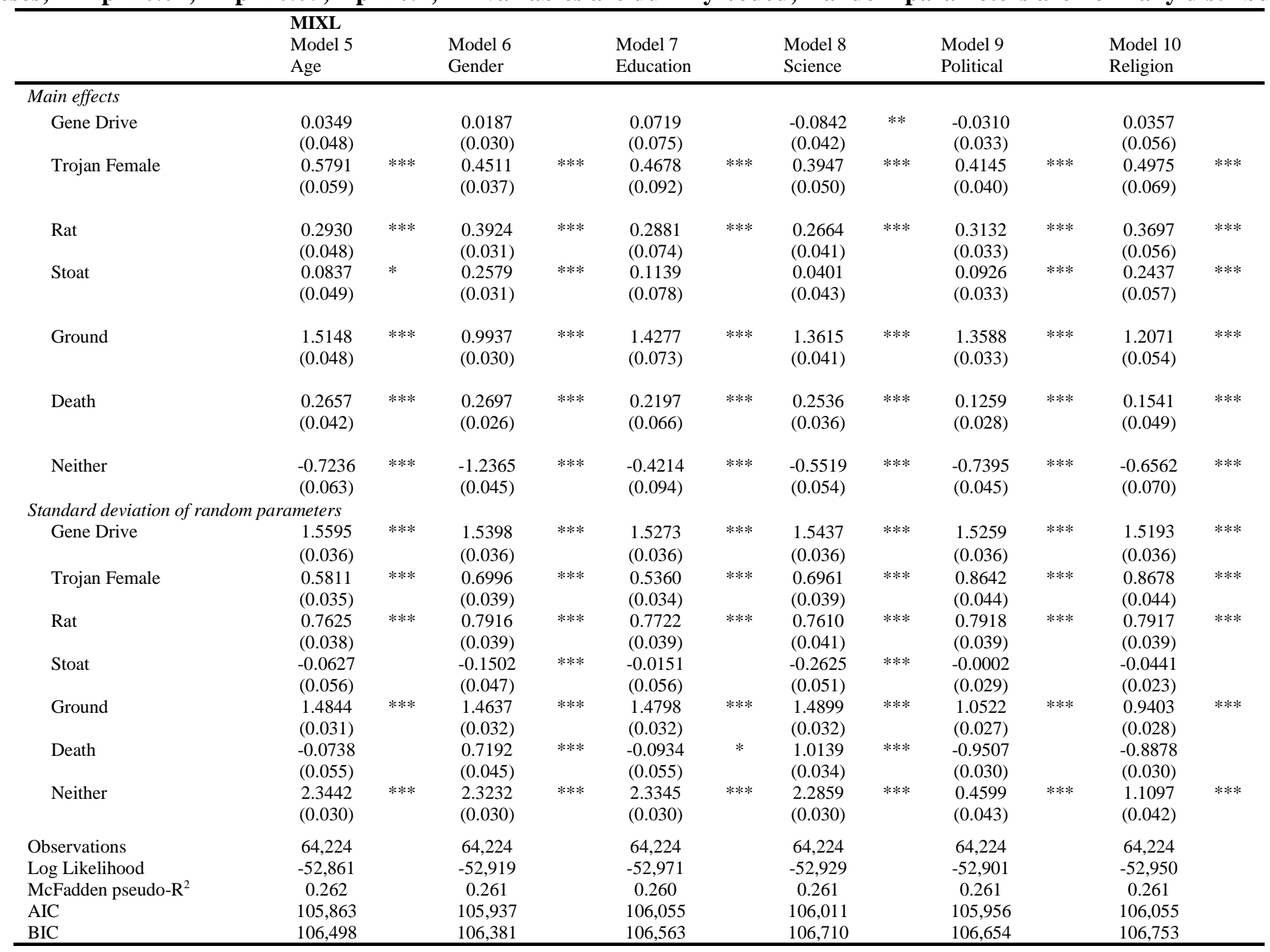


APPENDIX 4: General survey question on the perceived threat of pests

60

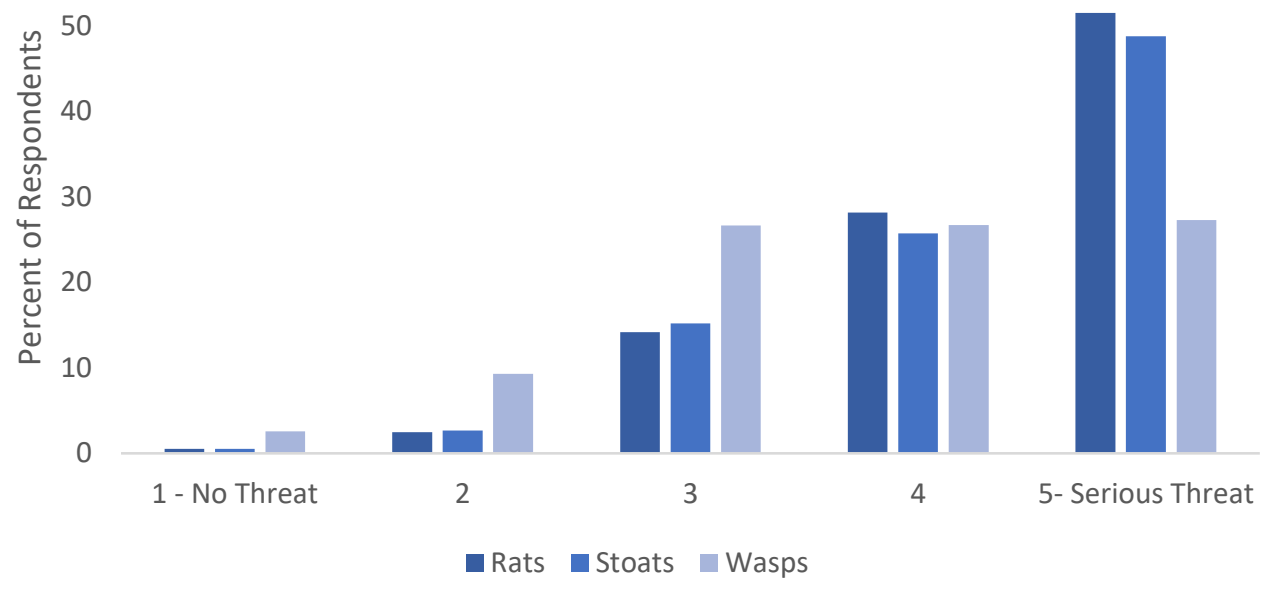

